\title{
Quantification of Aroma Compounds in Parmigiano Reggiano Cheese by a Dynamic Headspace Gas Chromatography-Mass Spectrometry Technique and Calculation of Odor Activity Value
}

\author{
Michael Qian ${ }^{1}$ and G. A. Reineccius \\ Department of Food Science and Nutrition, \\ University of Minnesota, St. Paul 55108
}

\begin{abstract}
Potentially important aroma compounds in Parmigiano Reggiano cheese were quantified. Free fatty acids were isolated with ion-exchange chromatography and quantified by gas chromatography. Neutral aroma compounds were quantified with a purge-trap/gas chromatography-mass spectrometry with selective mass ion technique. Odor activity values were calculated based on sensory thresholds reported in literature. The calculated odor activity values suggest that 3-methylbutanal, 2-methylpropanal, 2-methylbutanal, dimethyl trisulfide, diacetyl, methional, phenylacetaldehyde, ethyl butanoate, ethyl hexanoate, ethyl octanoate, acetic, butanoic, hexanoic, and octanoic acids are the most important aroma contributors to Parmigiano Reggiano cheese.
\end{abstract}

(Key words: Parmigiano Reggiano cheese, aroma, odor activity value, purge-trap)

Abbreviation key: OAV = odor activity value.

\section{INTRODUCTION}

Volatile compounds in Parmigiano Reggiano cheese have been extensively investigated (Lindsay, 1983; Woo and Lindsay, 1984; Meinhart and Schreier, 1986; Ha and Lindsay, 1991; Barbieri et al., 1994). By using gas chromatography (GC)/olfactometry techniques, Qian and Reineccius (2002) identified more than sixty odoractive compounds in this cheese. Application of aroma extract dilution analysis further reveals that acetaldehyde, 2-methylpropanal, 2-methylbutanal, 3-methylbutanal, phenylacetaldehyde, ethyl butanoate, ethyl hexanoate, ethyl octanoate, diacetyl, 2-heptanone, 2nonanone, dimethyltrisulfide, methional, 2,6-dimethylpyrazine, butanoic, hexanoic, octanoic, and decanoic

Received July 18, 2002.

Accepted September 16, 2002

Corresponding author: e-mail: Michael.qian@orst.edu.

${ }^{1}$ Current address: Department of Food Science and Technology, 100 Wiegand Hall, Oregon State University, Corvallis 97331. acids are probably responsible for the characteristic aroma of Parmigiano Reggiano cheese (Qian and Reineccius, 2003a,b). Because aroma exract dilution analysis is only a screening method (Grosch, 1993), the quantification of the potent odorants and the calculation of their odor activity values (OAV)are necessary to obtain a more accurate estimate of the contribution of each odorant to the flavor of this cheese.

Aroma compounds are usually present at very low concentrations in food and thus, tedious isolation and concentration processes are often needed to obtain an aroma concentrate for quantitative analysis. Complex sample preparation schemes often result in poor and inconsistent quantitative results. The dynamic headspace (purge-trap) technique is simple and reliable, and large amounts of analytes can be effectively concentrated and injected into the GC. As a result, this technique is very sensitive for trace level flavor analysis (Qian et al., 2002). The dynamic headspace-gas chromatography-mass spectrometry technique was used in this study to quantify neutral aroma compounds, while free fatty acids were isolated with ion-exchange chromatography and quantified by gas chromatography-flameionization dector. Odor activity values were then used to evaluate their potential aroma contribution.

\section{MATERIALS AND METHODS}

\section{Chemicals}

Free fatty acid standards were purchased from $\mathrm{Nu}$ Chek Prep, Inc. (Elysian, MN) and had purities greater than $99 \%$. All other chemical standards were purchased from Sigma-Aldrich with 98 to $100 \%$ purity unless specified. Pentane, hexane, isopropanol, and diethyl ether were purchased from Fisher Scientific.

\section{Cheese Sample}

The same Parmigiano Reggiano cheese sample as described previously (Qian and Reineccius, 2002) is used in this study. This cheese was manufactured in May of 1996 and had been aged for 24 mo. It was certified by 
the Consorzio Tutela Parmigiano Reggiano. The cheese contained $30.6 \%$ fat, $32.5 \%$ protein, and $29.2 \%$ moisture. This cheese was judged by several experienced cheese experts at Land O'Lakes, Inc. (Arden Hills, MN) and the cheese importer to be "typical." The cheese was carefully sliced from the center to the edge, so each slice had the same proportion of center cheese and crust. The cheese slices were wrapped with aluminum foil and stored at $-20^{\circ} \mathrm{C}$. Before the analysis, a slice of cheese was ground under liquid nitrogen with a blender, and the fine powder was used for analysis.

\section{Free Fatty Acid Determination}

Free fatty acids were determined using a method based on Jong and Badings (1990). Since pentanoic, heptanoic, and nonanoic acids were present at very low concentrations in this cheese compared with other even chain fatty acids, they were chosen as the internal standards. A mixture of pentanoic, heptanoic, and nonanoic acids was prepared by dissolving $100 \mathrm{mg}$ each of the acids in hexane-isopropanol (1:1) and diluting to 100 $\mathrm{ml}$ with the same solvent. Pentanoic acid was used to quantify acetic, butanoic, and hexanoic acids; heptanoic and nonanoic acids were used as internal standard for octanoic and decanoic acids, respectively. A standard stock solution containing acetic, butanoic, hexanoic, octanoic, and decanoic acids was prepared by dissolving $100 \mathrm{mg}$ of each fatty acid of interest in hexane-isopropanol (1:1) and diluting to $100 \mathrm{ml}$ with the same solvent. Working solutions with $50 \mu \mathrm{g} / \mathrm{ml}$ internal standard compounds and 5, 10, 25, 50,75, 100, and $150 \mu \mathrm{g} / \mathrm{ml}$ standard compounds were prepared from the stock solution.

Two grams of ground cheese sample was mixed with $1 \mathrm{ml}$ of $2 \mathrm{~N} \mathrm{H}_{2} \mathrm{SO}_{4}, 1.0 \mathrm{ml}$ of internal standard solution and $5 \mathrm{~g}$ of anhydrous $\mathrm{Na}_{2} \mathrm{SO}_{4}$. Twenty milliliters of hexane-isopropanol (1:1) was added to the mixture and then ground for $2 \mathrm{~min}$. The solution was then centrifuged, and the supernatant was saved. Five milliliters of this supernatant was passed through an amino propyl solid phase extraction column (J\&W Scientific, cat \# 188-1056, Folsom, CA) that had been conditioned with $10 \mathrm{~m}$ of heptane. After the solution had passed through, the solid phase extraction column was rinsed with $5 \mathrm{ml}$ of chloroform/isopropyl alcohol (2:1) to remove unbound lipids. The free fatty acids were then eluted with $5 \mathrm{ml}$ of diethyl ether-formic acid (98:2).

Free fatty acids were analyzed with a Hewlett Packard model 6890 GC. One microliter of sample was injected in a pulse-splitless mode. A HP-FFAP column (25 m X $0.32-\mathrm{mm}$ i.d. X $0.52-\mu \mathrm{m}$ film thickness) was used for separation. Helium was used as a carrier gas with a constant flow rate of $1 \mathrm{ml} / \mathrm{min}$. The $\mathrm{GC}$ oven temperature was set to $90^{\circ} \mathrm{C}$ for 2 min then raised to $240^{\circ} \mathrm{C}$ at a rate of $8^{\circ} \mathrm{C} / \mathrm{min}$ and held at $240^{\circ} \mathrm{C}$ for $10 \mathrm{~min}$. The injector temperature was set to $250^{\circ} \mathrm{C}$. A flameionization detector was used. The calibration curve of each fatty acid was constructed by using the actual concentration of both the standard and internal standard and their chromatographic peak areas by Chemstation software (www.chem.agilent.com). The concentrations of individual FFA were determined with Chemstation program.

\section{Quantification of Aroma Compounds by Dynamic Headspace-Gas Chromatography-Mass Spectrometry}

Aroma compounds of interest were divided into three groups based on their volatility, concentration, and interference. The first group of compounds consists of 2methylpropanal, 2-methylbutanal, 3-methylbutenal, 2butenal, 2-heptanone, ethyl butanoate, ethyl hexanoate, 3-methyl-1-butanol, and 2-heptanol. A $1000 \mathrm{mg} /$ $\mathrm{kg}$ standard stock solution was prepared by accurately weighing all of the standard compounds and dissolving them in $100 \mathrm{~g}$ of tricaprylin. Standard solution series of $1,5,10,25$, and $50 \mathrm{mg} / \mathrm{kg}$ were prepared from the stock solution by sequential dilution with tricaprylin. Internal standards were chosen based on their structural similarity, chromatographic resolution, and quantifying mass ions as shown in Table 1 . A $50 \mathrm{mg} / \mathrm{kg}$ internal standard solution containing 2-methyl-2-butenal, ethyl 2-butenoate, 3-heptanone, ethyl 3-hexenoate, 3-methyl-2-butanol, and 3-heptanol was prepared the same way as the standard solutions. The actual concentrations were corrected with their purities based on GC analysis. One gram of each standard solution was placed in the purge-trap sampling tube, and $0.1 \mathrm{~g}$ of the $50 \mathrm{mg} / \mathrm{kg}$ of internal standard solution was added into each standard solution. The tubes were placed in the purge-trap instrument for analysis. The standard calibration curve was constructed by using a GC-MS instrument (Agilent 6980-5972MSD) and Chemstation software.

The second group of compounds consists of propanal, butanal, 2-butenal, pentanal, hexanal, heptanal, and diacetyl. A $1000 \mathrm{mg} / \mathrm{kg}$ standard stock solution in tricaprylin was prepared as described previously. A series of working standard solutions $(0.1,0.25,0.5,1,2.5,5$, and $10 \mathrm{mgkg}$ ) were prepared from the standard solutions with tricaprylin used as the diluting solvent. A 1 $\mathrm{mg} / \mathrm{kg}$ internal standard solution was prepared from stable isotope 2-butanone $-4-\mathrm{d}_{3}$. One gram of each standard solution and $0.1 \mathrm{~g}$ of internal standard solution were placed into purge-trap sample tubes and then analyzed as described in the previous section. 
The third group consists of ethyl propanoate, ethyl pentanoate, dimethyltrisulfide, methional, phenylacetaldehyde, 2,6-dimethylpyrazine, 2-octanone, 2-nonanone, nonanal, decanal, and ethyl octanoate. A series of standard solutions ranging from 0.1 to $100 \mathrm{mg} / \mathrm{kg}$ was prepared. A $10 \mathrm{mg} / \mathrm{kg}$ solution of internal standards was prepared with ethyl 3-methylbutanoate, methyl propyl disulfide, deuterated acetophenenone-ring- $\mathrm{d}_{5}$, 2,3-dimethylpyrazine, and 3-octanone as described previously. One gram of each standard solution and $0.1 \mathrm{~g}$ of internal standard solution were used to build up the calibration curve.

Three sample sizes $(2,5$, and $10 \mathrm{~g})$ were used for analysis except for group three in which only two sample sizes ( 2 and $5 \mathrm{~g}$ ) were used. Triplicate analyses were performed for each sample size. One-tenth of a gram of internal standard solution was added to each cheese sample. After mixing well, the samples were equilibrated at $4^{\circ} \mathrm{C}$ for $24 \mathrm{~h}$ to allow the internal standards to diffuse into the cheese matrix. The sample was then placed in the purge-trap system for analysis.

The sample in the purge-trap system was equilibrated at $50^{\circ} \mathrm{C}$ for $60 \mathrm{~min}$ and purged for $40 \mathrm{~min}$ at the same temperature with helium at a flow rate of $20 \mathrm{ml} /$ min. After the purge process was complete, the trap was dry purged for $5 \mathrm{~min}$ to remove moisture. The volatiles were desorbed into the $\mathrm{GC}$ at $250^{\circ} \mathrm{C}$ for $4 \mathrm{~min}$. Chromatographic separation was performed on a DBwax column $(60-\mathrm{m} \mathrm{X} 0.32-\mathrm{mm}$ i.d. X $0.5-\mu \mathrm{m}$ film thickness) in series with a DB-1 column (5-m X 0.53-mm i.d. $\mathrm{X}$ 2.65- $\mu \mathrm{m}$ film thickness, J\&W Scientific, Folsom, CA) at the front. The oven temperature was initially held at $32^{\circ} \mathrm{C}$ for $4 \mathrm{~min}$ and then programmed from $32^{\circ} \mathrm{C}$ to $80^{\circ} \mathrm{C}$ at $3^{\circ} \mathrm{C} / \mathrm{min}$, from $80^{\circ} \mathrm{C}$ to $200^{\circ} \mathrm{C}$ at $4^{\circ} \mathrm{C} / \mathrm{min}$ and held at $200^{\circ} \mathrm{C}$, for $5 \mathrm{~min}$. The injector temperature was set at $250^{\circ} \mathrm{C}$ and split ratio was set at 10:1. A mass selective detector was used for quantification.

\section{Odor activity value}

The OAV was calculated by dividing the concentration of the compounds in the sample by the sensory thresholds obtained from the literature.

\section{RESULTS AND DISCUSSION}

Quantification of aroma compounds is very difficult due to extremely low concentration and inconsistent recovery. Proper internal standard compounds are needed for adequate quantification. Stable isotope labeled compounds have been used as the internal standards for aroma quantification. However, properly labeled compounds are generally not readily available, and synthesis and purification of such labeled com- pounds are extremely tedious procedures. Thus, we have chosen to quantify some of the analytes by selecting internal standards that have similar physical properties but not present in cheese or present at negligible concentrations. For example, 3-heptanone was used as the internal standard for 2-heptanone. High purity of 3heptanone is commercially available, and its properties are extremely similar to 2-heptanone. This compound is chromatographically well separated from other interfering peaks. In some cases, stable isotope compounds have to be used as the internal standards.

A sensitive dynamic headspace (purge-trap) technique was used for sample preparation to provide a solvent-free aroma concentrate for GC analysis. A DB1/DB-Wax dual-column was used for quantification because it gave a good separation of several critical pairs of volatiles, such as acetone and 2-methylpropanal and diacetyl and 2-pentanone.

Selective mass ion spectrometry was used in quantification to further eliminate potential interference and enhance sensitivity. The quantifying mass ions were selected based on principles of minimum interference and maximum sensitivity. For example, 2-methylpropanal and 2-butenal were well resolved from other compounds, the base peak ions were selected for quantification to achieve maximum sensitivity (Table 1). 2Methylbutanal and 3-methylbutanal were not completely resolved; however, quantifying mass ions of 57 for 2-methylbutanal and 44 for 3-methylbutanal permitted quantification of these two compounds.

The standard calibration curves for all of these aroma compounds were very good with linear correlation of coefficients $\left(R^{2}\right)$ greater than 0.98 for most of the compounds (Table 1). The quantitative results were reproducible considering low concentrations of aroma compounds. Because of a concern that the sample size may affect the volatility and the efficiency of volatile transfer by the purge-trap system, two or three sample sizes were used. For most compounds, there was no significant difference between the sample sizes. Thus, the average value was reported.

The aroma compounds in Parmigiano Reggiano cheese have never been quantified before; there is no literature available to verify the results. However, several aroma compounds were measured in Emmentaler (Preininger and Grosch, 1994) and Camembert (Kubícková and Grosch, 1998) cheeses. The concentrations of hexanal, diacetyl, dimethyl trisulfide, and methional were similar to those found in Camembert cheese, while the concentrations of 3 -methylbutanal, ethyl butanoate, ethyl hexanoate, and 2-heptanone were substantially higher than those found in Emmental and Camembert cheeses (Table 2). 
Table 1. Quantification of odorants in Parmigiano Reggiano Cheese.

\begin{tabular}{|c|c|c|c|}
\hline Internal standard & Odorants quantified ${ }^{1}$ & Target ion $(\mathrm{s})^{2}$ & Coef. of det. $\left(\mathrm{R}^{2}\right)$ \\
\hline \multirow[t]{5}{*}{ 2-Methyl-2-butenal } & & 84 & \\
\hline & 2-Methylpropanal & 43 & 0.996 \\
\hline & 2-Methylbutanal & 57 & 0.999 \\
\hline & 3-Methylbutanal & 44 & 0.999 \\
\hline & 2-Butenal & 70 & 0.998 \\
\hline \multirow[t]{2}{*}{ Ethyl 2-butenoate } & & 69 & \\
\hline & Ethyl butanoate & 71 & 0.998 \\
\hline \multirow{2}{*}{ Ethyl 3-hexenoate } & & 69 & \\
\hline & Ethyl hexanoate & 88 & 0.996 \\
\hline \multirow[t]{7}{*}{ 2-Butanone-4-d3 } & & 75 & \\
\hline & Propanal & 58 & 0.998 \\
\hline & Butanal & 72 & 0.985 \\
\hline & Pentanal & 44 & 0.994 \\
\hline & Hexanal & 44 & 0.998 \\
\hline & Heptanal & 70 & 0.990 \\
\hline & Diacetyl & 43 & 0.995 \\
\hline \multirow[t]{3}{*}{ Ethyl 2-methylpropanoate } & & 43 & \\
\hline & Ethyl propanoate & 57 & 0.999 \\
\hline & Ethyl pentanoate & 88 & 0.999 \\
\hline \multirow[t]{3}{*}{ Methyl propyl disulfide } & & 122 & \\
\hline & Dimethyl trisulfide & 126 & 0.997 \\
\hline & Methional & 104 & 0.934 \\
\hline \multirow[t]{2}{*}{ Acetophenone-ring-d5 } & & 110 & \\
\hline & Phenylacetaldehyde & 91 & 0.982 \\
\hline \multirow{2}{*}{ 2,3-Dimethylpyrazine } & & 108 & \\
\hline & 2,6-Dimethylpyrazine & 108 & 0.986 \\
\hline \multirow[t]{2}{*}{ 3-Heptanone } & & 57 & \\
\hline & 2-Heptanone & 43 & 0.998 \\
\hline \multirow[t]{6}{*}{ 3-Octanone } & & 57 & \\
\hline & 2-Octanone & 58 & 0.998 \\
\hline & 2-Nonanone & 58 & 0.996 \\
\hline & Nonanal & 59 & 0.987 \\
\hline & Decanal & 57 & 0.925 \\
\hline & Ethyl octanoate & 88 & 0.986 \\
\hline \multirow[t]{2}{*}{ 3-methyl-2-butanol } & & 45 & \\
\hline & 3-Methyl-1-butanol & 55 & 0.990 \\
\hline \multirow[t]{2}{*}{ 3-Heptanol } & & 59 & \\
\hline & 2-Heptanol & 45 & 0.999 \\
\hline
\end{tabular}

${ }^{1}$ The listed odorants were quantified using the volatile noted in the column to the left.

${ }^{2}$ Mass ions used for quanitification.

Free fatty acid concentrations in this cheese were slightly higher than that of $\mathrm{Ha}$ and Lindsay (1991), possibly due to the different samples used in the research. Acetic acid had not been measured in Parmigiano Reggiano cheese before; however, Mullin and Emmons (1997) investigated organic acids in several types of cheeses and found acetic acid concentrations ranged from 1000 to $2000 \mathrm{mg} / \mathrm{kg}$ in Brie, Camembert, Blue, Colby, and Brick cheeses. Thus, the value found for acetic acid in this Parmigiano Reggiano cheese is in agreement with other cheeses.

\section{Odor Activity Values}

The sensory threshold values reported in the literature vary tremendously depending on sample matrix, $\mathrm{pH}$, sample temperature, and the techniques employed in the experiments. The calculations of OAV and the comparisons of aroma contribution based on OAV are very difficult when sensory thresholds from different sources are used. Ideally, the sensory thresholds should have been determined in a cheese matrix. In this study, sensory thresholds in an oil phase were used for most of our compounds because there is no data available in a cheese matrix, and we assume that most of the odorants were preferentially dissolved in the oil phase of the cheese as opposed to the aqueous phase.

The OAV of aroma compounds are listed in Table 3. 3 -Methylbutanal had an OAV of 126, which suggested that it could be a significant contributor to the aroma of Parmigiano Reggiano cheese.

There were no reliable sensory threshold values in the literature for 2-methylpropanal or 2-methylbutanal in oil or cheese. When their sensory thresholds in malt culture were used, it was found both 2-methylpropanal and 2-methylbutanal had high OAV, so they were very likely important to the aroma of Parmigiano Reggiano cheese. 
Table 2. Aroma compound concentrations in Parmigiano Reggiano cheese measured by dynamic headspace technique.

\begin{tabular}{|c|c|c|c|c|}
\hline \multirow[b]{2}{*}{ Compounds } & \multirow[b]{2}{*}{ Concentrations (mg/kg) } & \multirow[b]{2}{*}{$\%$ RSD } & \multicolumn{2}{|c|}{ Literature } \\
\hline & & & $\begin{array}{l}\text { Emmentaler } \\
\text { (Preininger and } \\
\text { Grosch, 1994) }\end{array}$ & $\begin{array}{l}\text { Camembert } \\
\text { (Kubícková and } \\
\text { Grosch, 1998) }\end{array}$ \\
\hline 2-Methylpropanal & 0.52 & 14 & & \\
\hline 2-Methylbutanal & 0.49 & 12 & & \\
\hline 3-Methylbutanal & 0.68 & 15 & $0.064-0.087$ & $0.094-0.142$ \\
\hline Propanal & 0.025 & 16 & & \\
\hline Butanal & 0.008 & 11 & & \\
\hline 2-Butenal & 0.14 & 34 & & \\
\hline Pentanal & 0.02 & 5 & & \\
\hline Hexanal & 0.17 & 19 & & $0.124-0.144$ \\
\hline Heptanal & 0.04 & 31 & & \\
\hline Nonanal & 0.25 & 33 & & \\
\hline Decanal & 0.55 & 23 & & \\
\hline Ethyl propanoate & 0.03 & 17 & & \\
\hline Ethyl butanoate & 1.14 & 29 & $0.026-0.050$ & \\
\hline Ethyl pentanoate & 0.01 & 29 & & \\
\hline Ethyl hexanoate & 2.58 & 19 & $0.062-0.142$ & \\
\hline Ethyl octanoate & 1.62 & 19 & & \\
\hline 2-Heptanone & 1.84 & 23 & $0.363-0.380$ & \\
\hline 2-Octanone & 0.03 & 26 & & \\
\hline 2-Nonanone & 3.67 & 20 & & \\
\hline 3-Methyl-1-butanol & 0.19 & 47 & & \\
\hline 2-Heptanol & 0.97 & 16 & & \\
\hline Diacetyl & 0.026 & 10 & 0.098 & $0.074-0.11$ \\
\hline Dimethyl trisulfide & 0.03 & 20 & & $0.008-0.01$ \\
\hline Methional & 0.10 & 23 & $0.015-0.033$ & $0.027-0.125$ \\
\hline 2,6-Dimethylpyrazine & 0.32 & 27 & & \\
\hline Phenylacetaldehyde & 0.38 & 28 & & \\
\hline
\end{tabular}

Table 3. Odor activity value (OAV) of aroma compounds in Parmigiano Reggiano cheese.

\begin{tabular}{|c|c|c|c|c|c|}
\hline Compounds & $\begin{array}{l}\text { Concentrations } \\
(\mathrm{mg} / \mathrm{kg})\end{array}$ & $\begin{array}{l}\text { Sensory threshold } \\
(\mathrm{mg} / \mathrm{kg})\end{array}$ & Media & Reference & OAV \\
\hline 2-Methylpropanal & 520 & 100 & Malt culture & Margalith, 1981 & 5.2 \\
\hline 2-Methylbutanal & 490 & 130 & Malt culture & Margalith, 1981 & 3.8 \\
\hline 3-Methylbutanal & 680 & 5.4 & Oil & Preininger and Grosch, 1994 & 126 \\
\hline Propanal & 25 & 430 & Milk & Honkanen et al., 1964 & $<1$ \\
\hline 2-Butenal & 140 & 190 & Milk & Estimated & $<1$ \\
\hline Butanal & 8 & 190 & Milk & Honkanen et al., 1964 & $<1$ \\
\hline Pentanal & 20 & 70 & Butter & Siek et al., 1969 & $<1$ \\
\hline Hexanal & 170 & 120 & Oil & Kubícková and Grosch, 1998 & 1.4 \\
\hline Heptanal & 40 & 750 & Butter & Siek et al., 1969 & $<1$ \\
\hline Nonanal & 250 & 1000 & Butter & Siek et al., 1969 & $<1$ \\
\hline Phenylacetaldehyde & 380 & 20 & Skim milk & Sheldon and Lindsay, 1971 & 19 \\
\hline Ethyl butanoate & 1140 & 28 & Oil & Preininger and Grosch, 1994 & 40 \\
\hline Ethyl hexanoate & 2580 & 40 & Oil & Preininger and Grosch, 1994 & 64 \\
\hline Ethyl octanoate & 1620 & 32 & Water & Siek et al., 1971 & 50 \\
\hline Dimethyl trisulfide & 30 & 2.5 & Oil & Kubícková and Grosch, 1998 & 12 \\
\hline Diacetyl & 26 & 10 & Oil & Preininger and Grosch, 1994 & 3 \\
\hline Methional & 100 & 0.2 & Oil & Preininger and Grosch, 1994 & 480 \\
\hline 2-Heptanone & 1840 & 1500 & Oil & Preininger and Grosch, 1994 & 1 \\
\hline 2-Octanone & 30 & 3400 & Butter & Siek et al., 1969 & $<1$ \\
\hline 2-Nonanone & 3670 & 7700 & Cheese & Siek et al., 1969 & $<1$ \\
\hline 3-Methylbutanol & 96 & 4750 & Water & Karahadian et al., 1985 & $<1$ \\
\hline 2-Heptanol & 970 & 410 & Water & Siek et al., 1971 & 2 \\
\hline Acetic acid & $1,424,000$ & 32,300 & Phosphate butter, pH 5.7 & Guth and Grosch, 1993 & 44 \\
\hline Butanoic acid & 482,000 & 2700 & Phosphate butter, pH 5.7 & Guth and Grosch, 1993 & 179 \\
\hline Hexanoic acid & 260,000 & 27,100 & Aqueous solution, pH 5.6 & Warmke et al., 1996 & 10 \\
\hline Octanoic acid & 147,000 & 11,300 & Aqueous solution, pH 5.6 & Warmke et al., 1996 & 13 \\
\hline Decanoic acid & 283,000 & 14,800 & Aqueous solution, pH 5.6 & Warmke et al., 1996 & 19 \\
\hline
\end{tabular}


The OAV for most straight-chain aldehydes were less than one (below sensory detection thresholds), so these aldehydes were not likely to be important to the aroma of this cheese. Hexanal had an OAV of 1.4 and thus probably contributes to the aroma.

Phenylacetaldehyde, which has a floral honey-like aroma, had an OAV of 19 and is a likely contributor to the aroma of Parmigiano Reggiano cheese. Phenylacetaldehyde is considered important in Camembert cheese (Kubícková and Grosch, 1997); however, it has not been quantified before in any cheeses.

Ethyl butanoate, ethyl hexanoate, and ethyl octanoate all had very high OAV. Their OAV are 10 times higher than those found in Emmentaler cheese (Preininger and Grosch, 1994). The high OAV for these compounds indicate that they are likely to contribute to the characteristic fruity note of this cheese. Other esters were present below the sensory thresholds and, thus, are probably not important to aroma.

Dimethyltrisulfide, methional, and diacetyl appeared to contribute to this cheese aroma indicated by their high OAV. These compounds are important to many types of cheeses (Preininger and Grosch, 1994; Milo and Reineccius, 1997; Kubícková and Grosch, 1998).

The concentrations of most methyl ketones were below their sensory detection thresholds. The concentration of 2-heptanone was just at its detection threshold. They probably make minor, if any, contributions to the aroma of this cheese. Most alcohols were not important to the aroma of this cheese as indicated by their OAV (<1). 2-Heptanol had an OAV of 2 and might contribute to a fruity note. However, as indicated by their very high OAV, ethyl esters most likely contributed to the majority of fruity character of this cheese.

Many pyrazines have been identified in this cheese and are considered to be responsible for the nutty aroma (Qian and Reineccius, 2002). However, most of these compounds cannot be reliably quantified by the dynamic headspace technique due to their low volatility. 2,6-Dimethylpyrazine was quantified to have a concentration of $0.32 \mathrm{mg} / \mathrm{kg}$. The OAV was not calculated due to lack of reliable sensory data. Compounds responsible for the nutty flavor of Parmigiano Reggiano cheese need to be further studied.

Acetic, butanoic, hexanoic, octanoic, and decanoic acids had high OAV; thus, they likely contribute to the lipolyzed, cheesy aroma of this cheese.

\section{CONCLUSIONS}

This study showed that 3-methylbutanal, 2-methylpropanal, 2-methylbutanal, dimethyl trisulfide, diacetyl, methional, phenylacetaldyde, ethyl butanoate, ethyl hexanoate, ethyl octanoate, acetic acid, butanoic acid, hexanoic acid, and octanoic acid had high OAV and likely are key components to the aroma of Parmigiano Reggiano cheese. However, aroma compounds with nutty notes need to be further studied.

\section{ACKNOWLEDGMENT}

The authors thank Land O'Lakes, Inc., Arden Hills, Minnesota, for support of this project.

\section{REFERENCES}

Baldwin, R. E., and M. R. Cloninger. 1973. Flavor thresholds for fatty acids in buffered solutions. J. Food Sci. 38:528-530.

Barbieri, G., L. Bolzoni, M. Careri, A. Mangia, G. Parolari, S. Spagnoli, and R. Virgili. 1994. Study of the volatile fraction of Parmesan cheese. J. Agric. Food Chem. 42:1170-1176.

Collins, E. 1971. Steam volatile components of roasted barley. J. Agric. Food Chem. 19:533-539.

Grosch, W. 1993. Detection of potent odorants in foods by aroma extract dilution analysis. Trends Food Sci. Technol. 4:68-73.

Guth, H., and W. Grosch. 1993. Identification of potent odourants in static headspace samples of green and black tea powders on the basis of aroma extract dilution analysis (AEDA). Flavour and Fragr. J. 8:173-178.

Ha, J. K., and R. C. Lindsay. 1991. Volatile branched-chain fatty acids and phenolic compounds in aged Italian cheese flavors. J. Food Sci. 56:1241-1247, 1250.

Honkanen, E., P. Karvonen, and A. I. Virtanen. 1964. Studies on the transfer of some flavor compounds to milk. Acta Chem. Scand. 18:612.

Jong, C. D., and H. T. Badings. 1990. Determination of free fatty acids in milk and cheese, procedures for extraction, clean up, and capillary gas chromatographic analysis. J. High Res. Chromatagr. 13: 94-98.

Karahadian, C., D. B. Josephson, and R. C. Lindsay. 1985. Contribution of Penicillium sp. to the flavors of Brie and Camembert cheese. J. Dairy Sci. 68:1865-1877.

Kubícková, J., and W. Grosch. 1997. Evaluation of potent odorants of Camembert cheese by dilution and concentration techniques. Int. Dairy J. 7:65-70.

Kubícková, J., and W. Grosch. 1998. Quantification of potent odorants in Camembert cheese and calculation of their odour activity values. Int. Dairy J. 8:17-23.

Lindsay, R. C. 1983. Analysis of free fatty acids in Italian cheese. Dairy Field 166:20-21.

Margalith, P. Z. 1981. Page 32 in dairy products "Flavor Microbiology." C. C. Thomas, Springfield, IL.

Meinhart, E., and P. Schreier. 1986. Study of flavor compounds from Parmigiano Reggiano cheese. Milchwissenschaft 41:689-691.

Milo, C., and G. A. Reineccius. 1997. Identification and quantification of potent odorants in regular-fat and low-fat mild cheddar cheese. J. Agric. Food Chem. 45:3590-3594.

Mullin, W. J., and D. B. Emmons. 1997. Determination of organic acids and sugars in cheese, milk and whey by high performance liquid chromatography. Food Res. Int. 30:147-151.

Preininger, M., and W. Grosch. 1994. Evaluation of key odorants of the neutral volatiles of Emmentaler cheese by the calculation of odour activity values. Lebensmittel-Wissenschaft Technolo. 27:237-244.

Qian, M., S. Bloomer, and C. Nelson. 2002. Evaluation of fat-derived aroma compounds in Blue cheese by dynamic headspace gas chromatography/Olfactometry-mass spectrometry. J. Am. Oil Chem. Soc. 79:663-667.

Qian, M., and G. Reineccius. 2002. Identification of aroma compounds in Parmigiano Reggiano cheese by gas chromatography/olfactometry. J. Dairy Sci. 86:1362-1369. 
Qian, M., and G. Reineccius, 2003a. Potent aroma compounds in Parmigiano Reggiano cheese by a dynamic headspace (PurgeTrap) method. Flavour and Fragr. J. (Accepted).

Qian, M., and G. Reineccius, 2003b. Aroma extract dilution analysis of Parmigiano Reggiano cheese. J. Food Sci. (Accepted).

Sheldon, R. M., R. C. Lindsay, L. M. Libbey, and M. E. Morgan. 1971. Chemical nature of malty flavor and aroma produced by Streptococcus lactis var. maltigenes. Appl. Microbiol. 22:263-266.

Siek, T. J., I. A. Albin, L. A. Sather, and R. C. Lindsay. 1969. Taste thresholds of butter volatiles measured in butteroil. J. Food Sci. $34: 265-267$.
Siek, T. J., I. A. Albin, L. A. Sather, and R. C. Lindsay. 1971. Comparison of flavor thresholds of aliphatic Lactones with those of fatty acids, esters, aldehydes, alcoholes, and ketones. J. Dairy Sci. $54: 1-4$.

Warmke, R., H.-D. Belitz, and W. Grosch. 1996. Evaluation of taste compounds of Swiss cheese (Emmentaler). Z. Lebensm.-Unters. Forsch. 203:230-235.

Woo, A. H., and R. C. Lindsay. 1984. Concentration of major free fatty acids and flavor development in Italian cheese varieties. J. Dairy Sci. 67:960-968. 